\title{
Sinopse das espécies de Croton L. (Euphorbiaceae) no estado de Pernambuco, Brasil ${ }^{1}$
}

\author{
Juliana Santos Silva ${ }^{2,6}$, Margareth Ferreira de Sales ${ }^{3}$, Ana Paula de Souza Gomes ${ }^{4}$ e Daniela Santos Carneiro-Torres ${ }^{5}$
}

Recebido em 5/07/2009. Aceito em 4/03/2010

RESUMO - (Sinopse das espécies de Croton L. [Euphorbiaceae] no estado de Pernambuco, Brasil). Este estudo foi baseado na análise de materiais de herbário, referências bibliográficas e coletas, revelando a ocorrência de 35 espécies do gênero Croton para o estado de Pernambuco. A maior parte destas espécies tem distribuição exclusiva na zona fitogeográfica das Caatingas; Croton fuscescens Spreng., C. grewioides Baill. e C. blanchetianus Baill. estendem-se da zona da Mata até a zona das Caatingas; C. polyandrus Spreng. e C. sellowii Baill. ocorrem principalmente na faixa litorânea, em vegetação de restinga; C. argenteus L., C. jacobinensis Baill. e C. triqueter Lam. foram observados apenas na zona da Mata, e C. glandulosus L., C. heliotropiifolius Kunth, C. hirtus L' Her. e C. lundianus (Didr.) Müll. Arg. apresentam ampla distribuição no Estado. São apresentadas chave de identificação, comentários sobre distribuição geográfica e habitats, juntamente com ilustrações de características diagnósticas das espécies.

Palavras-chave: Crotonoideae, diversidade, distribuição geográfica, taxonomia

\begin{abstract}
Synopsis of the species of Croton L. (Euphorbiaceae) in Pernambuco state, Brazil.). This study was based on the analysis of herbarium material, specialized bibliography and field collections, recording the occurrence of 35 species of the genus Croton for the state of Pernambuco. Most of these species are distributed exclusively in the Caatinga phytogeographic region; Croton fuscescens Spreng., C. grewioides Baill. and C. blanchetianus Baill. are found from the forest zone to the caatinga zone; C. polyandrus Spreng. and C. sellowii Baill. occur mainly along the coast, in restinga vegetation; C. argenteus L., C. jacobinensis Baill. and C. triqueter Lam. were observed only in the forest zone, and C. glandulosus L., C. heliotropiifolius Kunth, C. hirtus L' Her. and C. lundianus (Didr.) Müll. Arg. are widely distributed. Identification keys, comments on geographic distribution and habitats and illustrations of diagnostic characteristics of the species are provided.
\end{abstract}

Key words: Crotonoideae, diversity, geographic distribution, taxonomy

\section{Introdução}

Croton L., com cerca de 1.200 espécies, é o segundo maior gênero da família Euphorbiaceae s.s (Govaerts et al. 2000; Berry et al. 2005). Tem distribuição pantropical, embora a maioria dos seus representantes ocorra nas Américas. Na América do Sul, o Brasil é o país que congrega o maior número de espécies, aproximadamente 350 (Berry et al. 2005), amplamente distribuídas nos mais diversos ambientes, destacando-se o cerrado, a caatinga e os campos rupestres.

Croton pertence à tribo Crotoneae, juntamente com Ophellantha Standl., Sandwithia Lanj., Sagotia Baill., Brasiliocroton P. E. Berry \& Cordeiro e Astraea Klotzch., diferindo destes por apresentar dobramento dos filetes no botão floral, associados às inflorescências tirsóides e as pétalas reduzidas ou ausentes nas flores pistiladas (Berry et al. 2005; Wurdack et al. 2005). Tratamentos sistemáticos mais abrangentes sobre este táxon foram propostos por Baillon (1864), Grisebach (1864), Müller (1865, 1866) e, recentemente por Webster $(1992,1993,1994)$. Destaca-se especialmente o trabalho de Webster (1993), que reconheceu 40 seções e cinco subseções para Croton.

Estudos filogenéticos macromoleculares demonstram que o gênero Croton, como tradicionalmente circunscrito, não constitui um táxon monofilético (Berry et al. 2005; Wurdack et al. 2005). Além disso, sugerem que para Croton tornar-se um grupo monofilético é necessário a inclusão de Moacroton Croizat. e a exclusão de Croton seção Astraea (Klotzsch) Baill.

No Nordeste brasileiro, trabalhos evidenciaram a alta diversidade de Croton, tais como: Cordeiro (1995), na Flora do Pico das Almas (BA), reconheceu dez espécies. Posteriormente, Carneiro et al. (2002), tratando as Euphorbiaceae dos inselbergs da região de Milagres (BA), registraram a ocorrência de sete espécies de Croton. Lucena (2000) analisou 14 espécies ocorrentes na Zona do Litoral e da Mata de Pernambuco. Cordeiro \& Carneiro-Torres (2006) listaram 52 espécies do gênero para o checklist das plantas do Nordeste brasileiro, Silva et al. (2009) tratou 15 espécies ocorrentes na microrregião do Vale do Ipanema (PE) e Carneiro-Torres (2009), reconheceu 68 espécies para o Bioma Caatinga. Apesar desses estudos, ainda há necessidade de mais trabalhos taxonômicos sobre o gênero.

Considerando a expressiva representação de Croton na flora de Pernambuco, o elevado número de espécimes encontrados sem identificação nos herbários pernambucanos e a complexa morfologia do gênero, este trabalho teve como objetivo facilitar o reconhecimento das espécies ocorrentes nesse estado, através de uma chave de identificação e comentários sobre distribuição geográfica e aspectos ecológicos de cada táxon.

\footnotetext{
Parte da dissertação de Mestrado da primeira Autora

2 Universidade Federal Rural de Pernambuco, Programa de Pós-Graduação em Botânica, Recife, PE, Brasil

3 Universidade Federal Rural de Pernambuco, Departamento de Biologia, Área de Botânica, Recife, PE, Brasil

${ }^{4}$ Faculdade de Integração do Sertão, Serra Talhada, PE, Brasil

5 Universidade Estadual do Sudoeste da Bahia, Campus Jequié, Jequié, BA, Brasil

6 Autor para correspondência: jullybandeira@hotmail.com
} 


\section{Material e métodos}

Área de estudo - o estado de Pernambuco, com $98.281 \mathrm{Km}^{2}$ de área superficial, situa-se entre as coordenadas $7^{\circ} 15^{\prime} 45^{\prime \prime}$ e $9^{\circ} 28^{\prime} 18^{\prime \prime}$ S e $34^{\circ} 48^{\prime}$ $35^{\prime}$ " e $41^{\circ} 19^{\prime} 54^{\prime \prime} \mathrm{W}$ (Andrade-Lima 1957). Está dividido em quatro zonas fitogeográficas: do Litoral, da Mata, das Caatingas e das Savanas (AndradeLima 1957). A zona da Mata foi dividida, ainda, nas subzonas da Mata Seca e da Mata Úmida; a zona das Caatingas nas subzonas do Agreste, Sertão e Matas Serranas; e a zona das Savanas em Tabuleiros e Agrestes do Araripe. Na subzona do Sertão, aquele autor reconheceu ainda as regiões do Sertão Central, do Jatinã, do São Francisco, do Araripe e dos Chapadões Cretáceos. Possui clima, solos e fitofisionomias heterogêneas, embora o clima semi-árido com vegetação de caatinga seja a predominante e ocupe cerca de $80 \%$ do estado. Há ainda, nas zonas do Litoral e da Mata, fragmentos de florestas ombrófilas e estacionais, em geral fragmentadas, além de corpos de mangues, restingas, dunas e ecossistemas associados (Andrade-Lima 1957). Na zona das Caatingas, além do predomínio da vegetação de caatinga, encontram-se também as formações rupestres e os brejos de altitude, sendo estes últimos enclaves de florestas perenifólias a semi-decíduas em altitudes acima de 780 m (Sales et al. 1998). O Arquipélago de Fernando de Noronha é um distrito de Pernambuco, mas não foi incluído neste estudo.

Estudo taxonômico - as coletas foram realizadas em diferentes municípios de Pernambuco entre março de 2006 e setembro de 2008, para observação das populações em campo e obtenção de material botânico, de acordo com a metodologia de Mori et al. (1989). Após o processamento, o material coletado foi depositado no acervo do Herbário Professor Vasconcelos Sobrinho (PEUFR) da Universidade Federal Rural de Pernambuco. Foram examinadas ainda exsicatas provenientes dos herbários BHCB, ESA, ESAL, HST, HUEFS, IAN, IBGE, IPA, PEUFR, R, UFP, UB, VIC, listados conforme Holmgren et al. (1990). A identificação dos espécimes foi baseada principalmente em Müller (1873), nos protólogos e em imagens da coleção-tipo. A padronização da terminologia das estruturas vegetativas e reprodutivas baseou-se em Radford et al. (1974) e Harris \& Harris (1994). Para os comentários de distribuição geográfica das espécies, adotou-se a classificação fitogeográfica de Pernambuco proposta por Andrade-Lima (1957).

\section{Resultados e discussão}

Em Pernambuco foram registradas 35 espécies do gênero Croton, o que representa 24\% das espécies de Euphorbiaceae ocorrentes no estado (139 spp.). A maioria delas (31) ocorre na zona fitogeográfica das Caatingas, embora algumas espécies (Croton fuscescens, C. grewioides, $C$. blanchetianus e $C$. heliotropiifolius) sejam também encontradas na zona fitogeográfica da Mata. Merece destaque a microrregião do Vale do Ipanema (municípios de Águas Belas, Buíque, Itaíba, Pedra, Tupanatinga e Venturosa), na qual o gênero está representado por 15 espécies. Destas, quatro (C. corchoropsis, C. nummularius, C. rudolphianus, C. virgultosus) só foram encontradas na chapada de São José, em Buíque (Silva et al. 2009). Verificamos também a ocorrência de duas espécies de Astraea Klotzsch em Pernambuco, que até pouco tempo, eram consideradas como Croton, a saber: A. klotzschii Didr. e A. lobata (L.) Klotzsch.

As espécies são comumente subarbustivas ou arbustivas, monóicas e, menos frequentemente, arbóreas (Croton floribundus e C. polyandrus). O indumento é constituído por tricomas estrelados, dendríticos, fasciculados, lepidotos, simples ou estados intermediários entre estes tipos. As folhas são predominantemente alternas, às vezes opostas $(C$. tetradenius e C. sellowii) ou pseudo-verticiladas no ápice dos ramos (C. nummularius), pecioladas, comumente sem glândulas e, menos frequentemente, estas estruturas são encontradas na porção distal do pecíolo, da superfície superior (acropeciolares - C. glandulosus, C. grewioides, C. hirtus, C. lundianus, $C$. salutaris, $C$. sincorensis e $C$. trinitatis) ou da superfície inferior, bem próximo à lâmina ( basilaminares - C. adamantinus, C. echioides, C. virgultosus e C. nepetifolius) ou, ainda, nestas duas posições no mesmo indivíduo (C. tetradenius) e ao longo da margem. As inflorescências são terminais, tirsóides, contínuas (na maioria das espécies) ou descontínuas entre as címulas estaminadas e pistiladas, neste caso exibindo a porção mediana da raque sem flores (C. lundianus e C. trinitatis). As flores estaminadas são, geralmente, uniformes em sua estrutura, diferindo apenas no tamanho, número de estames e indumento das sépalas e pétalas. São sempre pediceladas, diclamídeas, valvares e pêntameras. As sépalas são iguais entre si e unidas apenas na base. $\mathrm{O}$ androceu é composto por estames livres entre si, que são característicamente encurvados no botão. O número de estames varia de 7 a 55 . Os filetes são filiformes, vilosos (na maioria das espécies) ou glabros ( $C$. adamantinus, $C$. campestris, C. echioides, C. glandulosus, C. heliotropiifolius, C. lundianus, C. microcarpus, C. nepetifolius, C. tetradenius e $C$. virgultosus). As anteras são sempre basifixas, bitecas, introrsas e rimosas. O disco é geralmente formado por cinco glândulas opostas aos lobos do cálice. As flores pistiladas são muito mais variáveis na estrutura do que as estaminadas. São monoclamídeas, raramente diclamídeas, pediceladas ou sésseis. As sépalas são valvares ou às vezes imbricadas (C. polyandrus), unidas ou não na base, em número de cinco a seis (C. lundianus). Os lobos são lineares, ovais, estreitamente oblongos, elípticos, lanceolados ou com variações intermediárias entre estes. $\mathrm{O}$ disco nas flores pistiladas exibe pouca variação, sendo geralmente pentalobado e glabro. $\mathrm{O}$ ovário é sincárpico, tricarpelar, trilocular com um único óvulo por lóculo. Os estiletes são em número de três, geralmente, ramificados uma ou mais vezes. Podem ser livres, unidos na base ou, ainda, formar uma coluna $(C$. blanchetianus e C. floribundus) com os ramos ascendentes ou patentes sobre o ovário. $O$ fruto é uma cápsula septicidaloculicida, geralmente orbicular. A columela apresenta ápice inteiro ou tripartido. As sementes são carunculadas, lisas ou rugosas, geralmente com a face dorsal convexa, variando de paleáceas, castanho-alaranjadas, marrons a enegrecidas.

Chave para espécies de Croton do estado de Pernambuco

1. Sépalas das flores pistiladas reduplicadas

2. Pecíolo com glândulas ... 24. C. salutaris

2'. Pecíolo sem glândulas

3. Estiletes livres 
4. Estípulas 1,5-2 mm de comprimento com margem laciniado-glandular; limbo foliar com tricomas lepidotos em ambas as faces; estames 11 .....

25. C. sellowii

4'. Estípulas 5-15 mm de comprimento com margem inteira; limbo foliar com tricomas lepidotos apenas na face inferior; estames 15

5. Indumento foliar prateado a amarelado; brácteas ovais a triangulares; sépalas pistiladas triangulares; disco das flores de ambos os sexos com lobos livres; sementes lisas, marrons a acinzentadas.

27. Croton sp.

5'. Indumento foliar ferrugíneo a ferrugíneo-alaranjado; brácteas linear-lanceoladas; sépalas pistiladas elípticas a obovais; disco das flores de ambos os sexos com lobos unidos; sementes papiloso-rugosas, creme com máculas avermelhadas.

29. C. tricolor

3 '. Estiletes unidos na base, às vezes formando uma coluna

6. Pedicelo das flores pistiladas $0,5-4 \mathrm{~mm}$ de comprimento; pétalas das flores pistiladas ausentes; fruto não muricado

7. Limbo lanceolado a elíptico, face inferior uniformemente prateada a discretamente amarelada; disco das flores estaminadas lepidoto

4. C. argyrophyllus

7'. Limbo foliar largamente oval, face inferior esverdeada; disco das flores estaminadas tomentoso a glabro

8. Estiletes 12-16-fidos, unidos formando coluna; sementes lisas.

5. C. blanchetianus

8 . Estiletes 6-fidos, unidos apenas na base; sementes rugosas a foveolada

15. C. jacobinensis

6'. Pedicelo das flores pistiladas 6-9 $\mathrm{mm}$ de comprimento; pétalas das flores pistiladas filiformes; fruto muricado

9. C. floribundus

1'. Sépalas das flores pistiladas não reduplicadas

9. Folhas com margem inteira a levemente serrilhada

10. Sépalas das flores pistiladas de tamanho fortemente desigual, 2 lobos rudimentares com até $1 \mathrm{~mm}$ comprimento e

3 lobos maiores com 3-6 mm comprimento profundamente laciniados

11. Ramos com tricomas estrelados, inflorescência 10-15 mm, flor pistilada pedicelada, sementes lisas

3. C. argenteus

11'. Ramos com tricomas dendríticos, inflorescência $25-65 \mathrm{~mm}$, flor pistilada séssil a subséssil, sementes reticuladas

12. Folhas esparsamente serrilhadas, palmatinérvias, brácteas lineares a linear-lanceoladas, estames 11, estiletes 4-fidos, fruto esverdeado.

32. C. triqueter

12'. Folhas inteiras a diminutamente serrilhadas, peninérvias, brácteas espatuladas, estames 7-8, estiletes 2-fidos, fruto enegrecido.

10. C. fuscescens

10 '. Sépalas das flores pistiladas de tamanho igual à ligeiramente desigual

13. Estiletes 2-fidos

14. Indumento de tricomas dentado-lepidotos; folhas coriáceas; inflorescências com címulas bissexuais constituída por 1 flor pistilada e 2-5 estaminadas.

21. C. polyandrus

14'. Indumento de tricomas estrelados; folhas membranáceas a cartáceas; inflorescências com címulas unissexuais

15. Ápice das folhas tripartido.

30. C. tridentatus

15'. Ápice das folhas inteiro

16. Columela do fruto com ápice inteiro após a deiscência

17. Limbo com margem inteira, duas glândulas na base do limbo ou ápice do pecíolo, flores pistiladas sésseis

8. C. echioides

17'. Limbo com margem serrilhada, 4-6 glândulas na base do limbo ou ápice do pecíolo, flores pistiladas $1-3 \mathrm{~mm}$ comprimento

28. C. tetradenius

16'. Columela do fruto com ápice tripartido após a deiscência

18. Flores estaminadas em címulas unifloras; sementes rugosas

6. C. campestris

18'. Flores estaminadas reunidas em címulas com 2-5 flores; sementes lisas

19. Pecíolo com duas glândulas pateliformes; inflorescências laxas.... 22. C. rhamnifolioides

19'. Pecíolo normalmente sem glândulas ou, quando presentes, globosas; inflorescências congestas

20. Indumento dos ramos amarelado; folhas lanceolado-ovais; frutos vilosos

13. C. heliotropiifolius

20'. Indumento dos ramos ferrugíneo; folhas ovais; frutos pubescentes ......15. C. japirensis

13'. Estiletes 4-fidos

21. Ramos prateados; indumento de tricomas estrelado-lepitodos; flores pistiladas pediceladas $(3-7 \mathrm{~mm})$; fruto subgloboso a elipsóide, frequentemente encurvado no pedicelo

7. C. corchoropsis

21'. Ramos ferrugíneos; indumento de tricomas estrelados; flores pistiladas sésseis; fruto globoso. 
9'. Folhas com margem crenada, denteada, denteado-glandular, serreada, serreado-glandular ou bisserreada

22. Inflorescência com descontinuidade entre as címulas estaminadas e pistiladas, exibindo a porção mediana da raque sem flores

23. Flores pistiladas com 6 sépalas, obovais, margem discretamente serreada; ovário glabrescente a glabro

18. C. lundianus

23’. Flores pistiladas com 5 sépalas, elíptico-oblongas a elíptico-lanceoladas, margem inteira; ovário hirsuto a pubescente.

31. C. trinitatis

22'. Inflorescência sem descontinuidade entre as címulas estaminadas e pistiladas

24. Estípulas com glândulas

25. Folhas discolores com a face inferior velutina; estípulas laceradas; brácteas espatuladas, laceradas; estames 50-55; sépalas das flores pistiladas laceradas 17. C. laceratoglandulosus

$25^{\prime}$. Folhas concolores com a face inferior pubescente a tomentosa; estípulas inteiras; brácteas lanceoladas, oblongas a estreitamente triangulares, inteiras; estames 10-12; sépalas das flores pistiladas inteiras

26. Sépalas das flores pistiladas hirsuto-tomentosas com glândulas sésseis.

3. C. urticifolius

26'. Sépalas das flores pistiladas pubescentes a glabrescentes com glândulas estipitadas

27. Estípulas com glândulas sésseis obovóides, densamente aglomeradas; folhas com base cordada; inflorescências com 3,5-6 cm de comprimento

23. C. rudolphianus

27'. Estípulas com glândulas longamente estipitadas, esparsadas; folhas com base arredondada; inflorescências com 12-15 cm de comprimento

2. C. adenocalyx

24'. Estípulas sem glândulas

28. Estiletes 2-fidos

29. Brácteas com glândulas

30. Ramos tomentosos; glândulas das brácteas sésseis

11. C. glandulosus

30'. Ramos hirsutos; glândulas das brácteas longamente estipitadas 14. C. hirtus

29'. Brácteas sem glândulas

31. Planta fortemente aromática, aroma de canela, frequentemente, perceptível em material herborizado; filetes vilosos; sépalas pistiladas estreitamente oblongas.

12. C. grewioides

31'. Planta ligeiramente aromática; filetes glabros; sépalas pistiladas elípticas

32. Inflorescências $0,7-2,5 \mathrm{~cm}$; sépalas das flores pistiladas ovais com a base levemente unguiculada; pétalas ausentes nas flores pistilada

1.C. adamantinus

32'. Inflorescências 8-9,5 cm; sépalas das flores pistiladas lanceoladas, sem base unguiculada; pétalas presentes nas flores pistiladas

35. C. virgultosus

28'. Estiletes 4-fidos ou mais

33. Arbustos; folhas 7-10 x 3,5-5,5 cm, elípticas a ovais, glândulas no ápice do pecíolo, base ou na margem da lâmina; inflorescências 5,5-6,5 cm de comprimento; sépalas das flores pistiladas sem glândulas

34. Glândulas cilíndricas; estames 10; estiletes 8-fidos 26. C. sincorensis

34'. Glândulas pateliformes; estames 15-16; estiletes 4-6-fidos

19. C. nepetifolius

33'. Subarbustos; folhas 0,2-1 x 0,3-1 cm, orbiculares, glândulas ausentes; inflorescências 0,8-2,2 cm de comprimento; sépalas das flores pistiladas com glândulas estipitadas na margem.

20. C. nummularius

1. Croton adamantinus Müll. Arg., Fl. bras. 11(2): 115. 1873.

Fig. 1-4

Ocorre, com maior frequência, no semi-árido brasileiro, geralmente em regiões com altitudes variando entre $150 \mathrm{a}$ 1000 m. Distribui-se nos estados da Bahia, Ceará, Pernambuco, Piauí, Rio Grande do Norte, Sergipe até o norte de Minas Gerais. Na área de estudo ocorre exclusivamente na zona fitogeográfica das Caatingas, em vegetação de caatinga e formações rupestre.

Material selecionado: BRASIL: Pernambuco: Buíque, pedra do Cachorro, 13/II/2008, fl., Silva et al. 400 (PEUFR); sítios arqueológicos do Alcobaça, 13/II/2008, fl., Silva et al. 397 (PEUFR); Exu, 13/II/2007, fl., Carneiro-Torres, Silva-
Castro \& Cardoso 875 (HUEFS); Serrolândia, Chapada do Araripe, 11/II/1983, fl., Fotius 3634 (IPA, HUEFS); Sertânia, 8/XI/1986, fl., Webster, Dehgan \& Ataíde 25626 (IPA, HUEFS).

\section{Croton adenocalyx Baill., Adansonia 4: 344. 1864.}

Fig. 5-7

Espécie restrita ao semi-árido brasileiro, ocorrendo no Ceará, Paraíba, Pernambuco, Piauí, Rio Grande do Norte e Sergipe. Cresce em vegetação de caatinga sobre solo arenoso ou argilo-arenoso pedregoso, em altitudes que variam de $190 \mathrm{~m}$ a $530 \mathrm{~m}$. Em Pernambuco ocorre na zona fitogeográfica das Caatingas, em vegetação de caatinga e em áreas antropizadas. 
Material selecionado: BRASIL: Pernambuco: Betânia, serra dos Arrombados, 24/V/1971, fl., Academia Brasileira de Ciências 894 (HUEFS, IPA); Mirandiba, fazenda Tigre, 30/III/2006, fl., Lucena et al. 1166 (UFP).

\section{Croton argenteus L., Sp. Pl. 1004. 1753.}

Fig. 8-10

Espécie neotropical com ampla distribuição na Argentina, Belize, Bolívia, Brasil (AM, BA, MT, PA, PE, PI, MA, MS, RJ, RN), Colômbia, Costa Rica, El Salvador, Guatemala, Honduras, México, Nicaragua, Panamá, Paraguai, Peru e Venezuela. No Brasil, pode ser encontrada em áreas alagadiças, matas ciliares sobre solo arenoso, ocorrendo do nível do mar até $500 \mathrm{~m}$ de altitude. Em Pernambuco foi observada apenas na zona da Mata, crescendo na borda da mata, em solos arenosos.

Material selecionado: BRASIL: Pernambuco: Vitória de Santo Antão, estação experimental do Cedro-IPA, 25/ VIII/1958, Andrade-Lima 3231 (PEUFR).

4. Croton argyrophyllus Kunth in Humb., Bonpl. \& Kunth., Nov. gen. sp. pl. (4) 2: 68. 1817.

Fig. 11-16

Distribuição na porção norte da América do Sul (Bolívia, Colômbia, Paraguai e Venezuela) e no Brasil (Alagoas, Bahia, Ceará, Paraíba, Pernambuco, Piauí, Roraima, Rondônia e Sergipe). Ocorre principalmente em ambientes do semi-árido, sobre solos arenosos ou pedregosos em vegetação semidecidual a decidual. Em Pernambuco foi encontrada formando extensas populações na zona fitogeográfica das Caatingas (Agreste e Sertão), em vegetação de caatinga sobre solo arenoso ou pedregoso.

Nome vulgar: marmeleiro ou marmeleiro branco

Material selecionado: BRASIL: Pernambuco: Buíque, pedra do Cachorro, 13/II/2008, Silva et al. 399 (PEUFR); Floresta, Rebio Serra Negra, 9/III/1995, fl., Tschá \& Laurênio 31 (PEUFR); Pedra, 30/III/1991, fl., Pessoa s/n (PEUFR-12420); Venturosa, parque Pedra Furada, 17/I/1998, fl., Costa \& Rodal 7 (PEUFR).

\section{Croton blanchetianus Baill., Adansonia 4: 301. 1864.}

Fig. 17-22

Restrita ao semi-árido brasileiro, ocorrendo tanto em vegetação de caatinga quanto de carrasco, distribuindo-se nas regiões Nordeste (AL, BA, CE, PE, PI, PB, RN, SE) e Sudeste (MG). Em Pernambuco, foi verificada a partir da zona da Mata até a zona das Caatingas em diversos ambientes, incluindo áreas de caatinga, bordas das florestas montanas (brejos de altitude), capoeiras, margem de estrada e cultivos abandonados.

Nome vulgar: marmeleiro

Material selecionado: BRASIL: Pernambuco: Limoeiro, Gameleira, 12/V/1998, fl., Lucena \& Laurênio 476
(PEUFR); Mirandiba, estrada para fazenda Troncão, 16/ IV/2007, fl., Silva et al. 161 (UFP); Taquaritinga do Norte, 753'24'S, 36005'59”'W, 18/IV/1997, fl., Laurênio et al. 481 (PEUFR).

6. Croton campestris A. St.-Hil., Pl. Usuel. Bras. pt. 12 tab. 60. 1827.

Fig. 23-25

Amplamente distribuída no Brasil, ocorrendo nas regiões Centro-oeste (DF, GO, MS), Nordeste (AL, BA, CE, PE, PI, PB, RN), Sul (PR, RS) e Sudeste (ES, MG, RJ, SP) (Lima \& Pirani 2003). É encontrada desde áreas com altitudes mais elevadas (1346 m), na Cadeia do Espinhaço até o nível do mar, em regiões de mata ciliar, cerrado, campo limpo, campo sujo, caatinga. É uma espécie pouco frequente na área de estudo, tendo sido coletada apenas no município de Petrolândia, em áreas antropizadas.

Nome vulgar: velame

Material selecionado: BRASIL: Pernambuco: Petrolândia, 15/II/1984, fl., Fotius 3761 (IPA, HUEFS).

\section{Croton corchoropsis Baill., Adansonia 4: 364. 1864.}

Fig. 66-69

Ocorre em áreas secas das Regiões Centro-Oeste (Goiás), Norte (Tocantins), Nordeste (Bahia, Maranhão e Pernambuco) e Sudeste (Minas Gerais e São Paulo). Em Pernambuco é uma espécie conhecida por poucas coletas, sendo observada apenas em formações rupestres no município de Buíque, em altitudes acima de $900 \mathrm{~m}$.

Material selecionado: BRASIL. Pernambuco: Buíque, Chapada São José, 3/IV/2000, fl., Sales 1060 (IPA); fazenda Botija, 6/V/2003, fl., Laurênio \& Gomes 2016 (PEUFR); serra de Jerusalém, 14/II/2008, fl. fr., Silva et al. 403 (HST, PEUFR).

\section{Croton echioides Baill., Adansonia 4: 334. 1864.}

Fig. 26-28

Trata-se de uma espécie restrita ao semi-árido brasileiro, crescendo em vegetação de caatinga (AL, BA, CE, MG, PE, PI, PB, RN), embora também seja observada em áreas transicionais de caatinga-cerrado e cerrado do estado do Piauí. Em Pernambuco está associada às chapadas de formações areníticas, comumente encontrada em altitudes que variam de 700 a 900 metros de altitude.

Material selecionado: BRASIL: Pernambuco: Buíque, fazenda Botija, 6/V/2003, fl., Gomes \& Laurênio 1106 (PEUFR); Paraíso Selvagem, 8/V/2003, fl. fr., Laurênio 2035 (PEUFR); serra de Jerusalém, 14/II/2008, fl., Silva et al. 402 (HST, PEUFR); Serrolândia, Chapada do Araripe,15/ II/1984, fl., Fotius 3761 (IPA).

9. Croton floribundus Spreng., Syst. Veg. 3: 873. 1826.

Fig. 29-32 

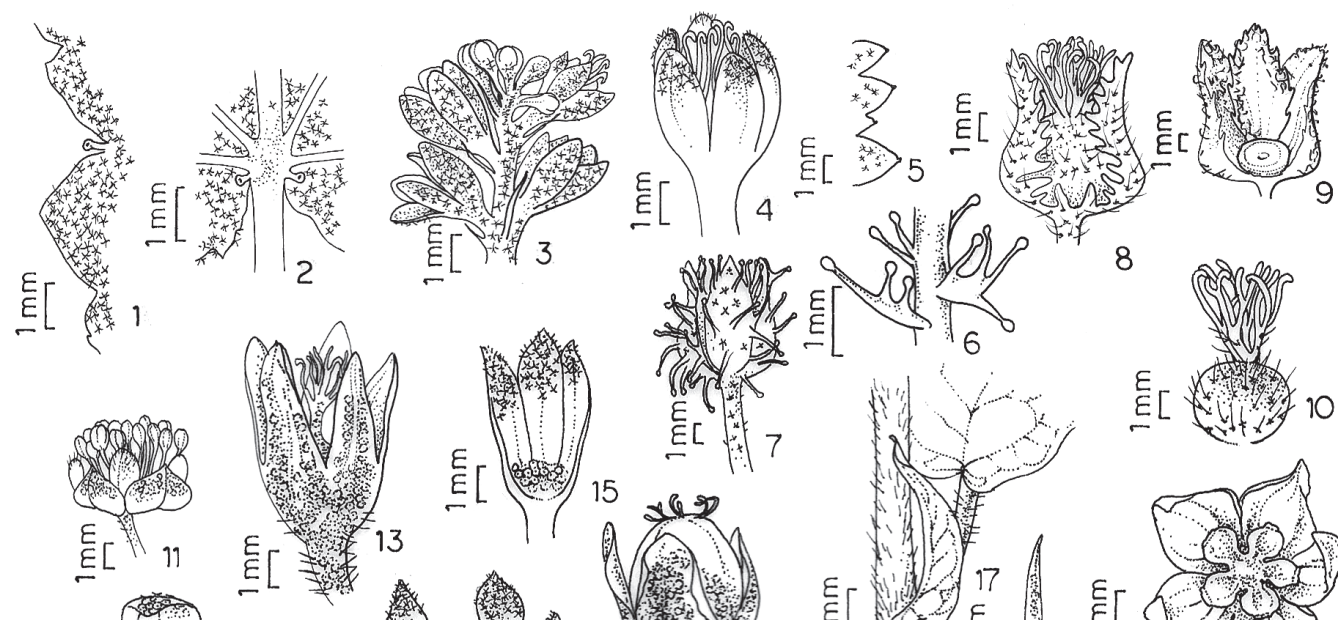

20) 8
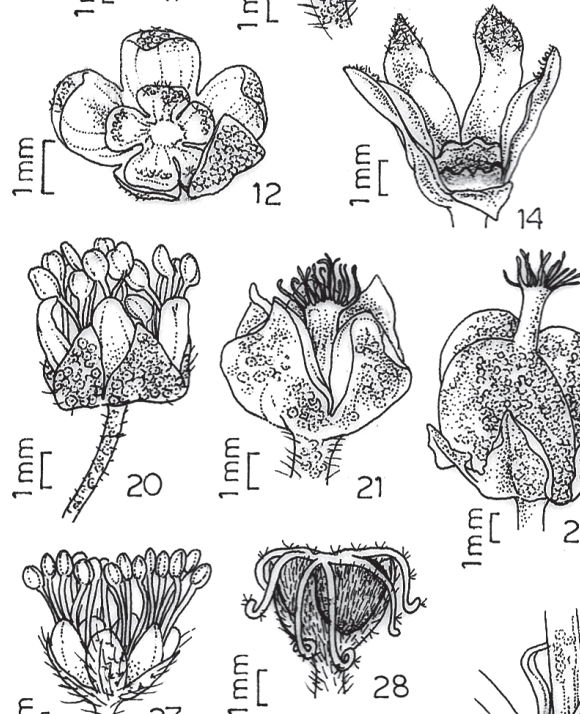

$\underline{\varepsilon}[$
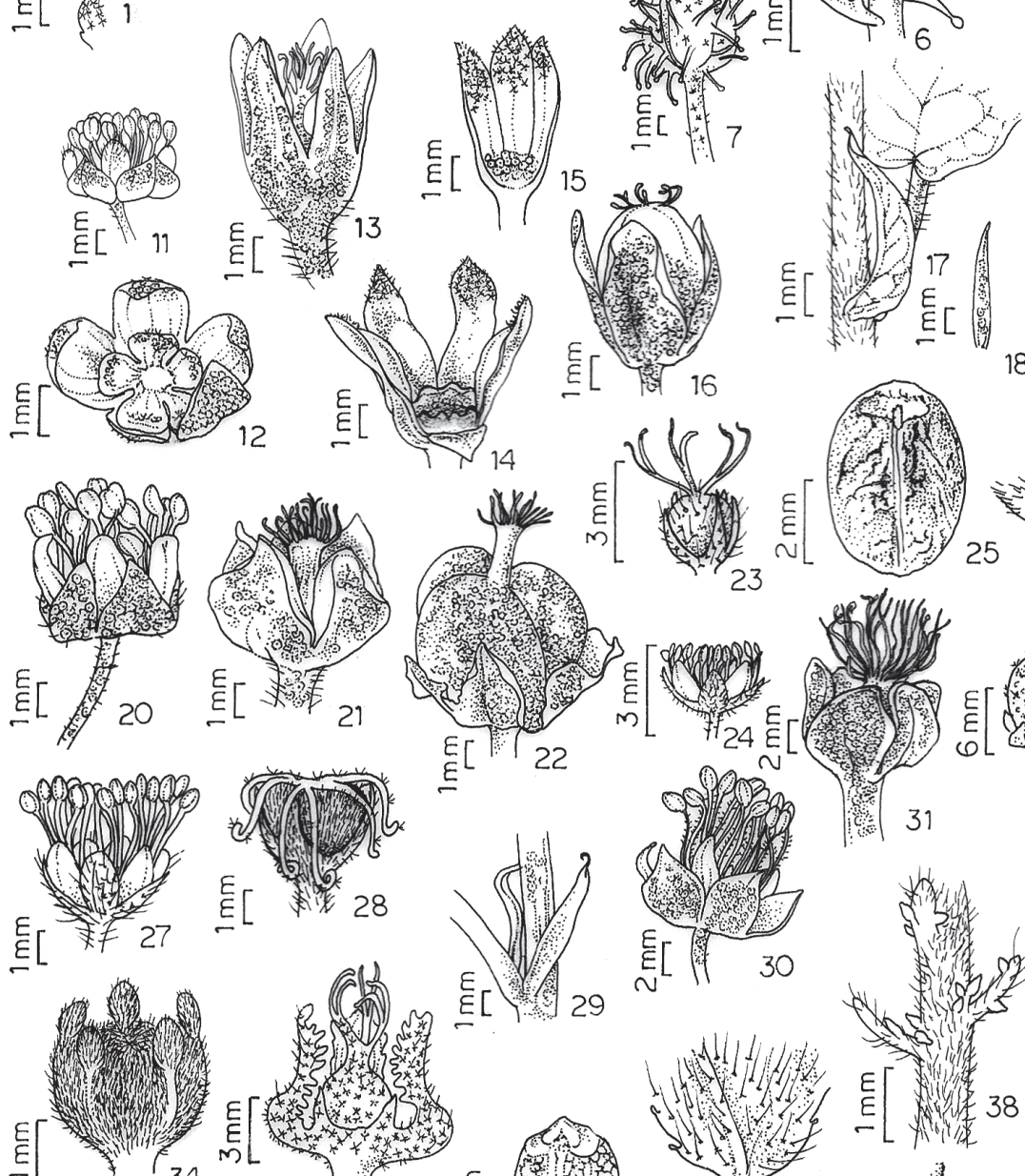

8 (8) E[ 7

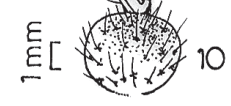

18
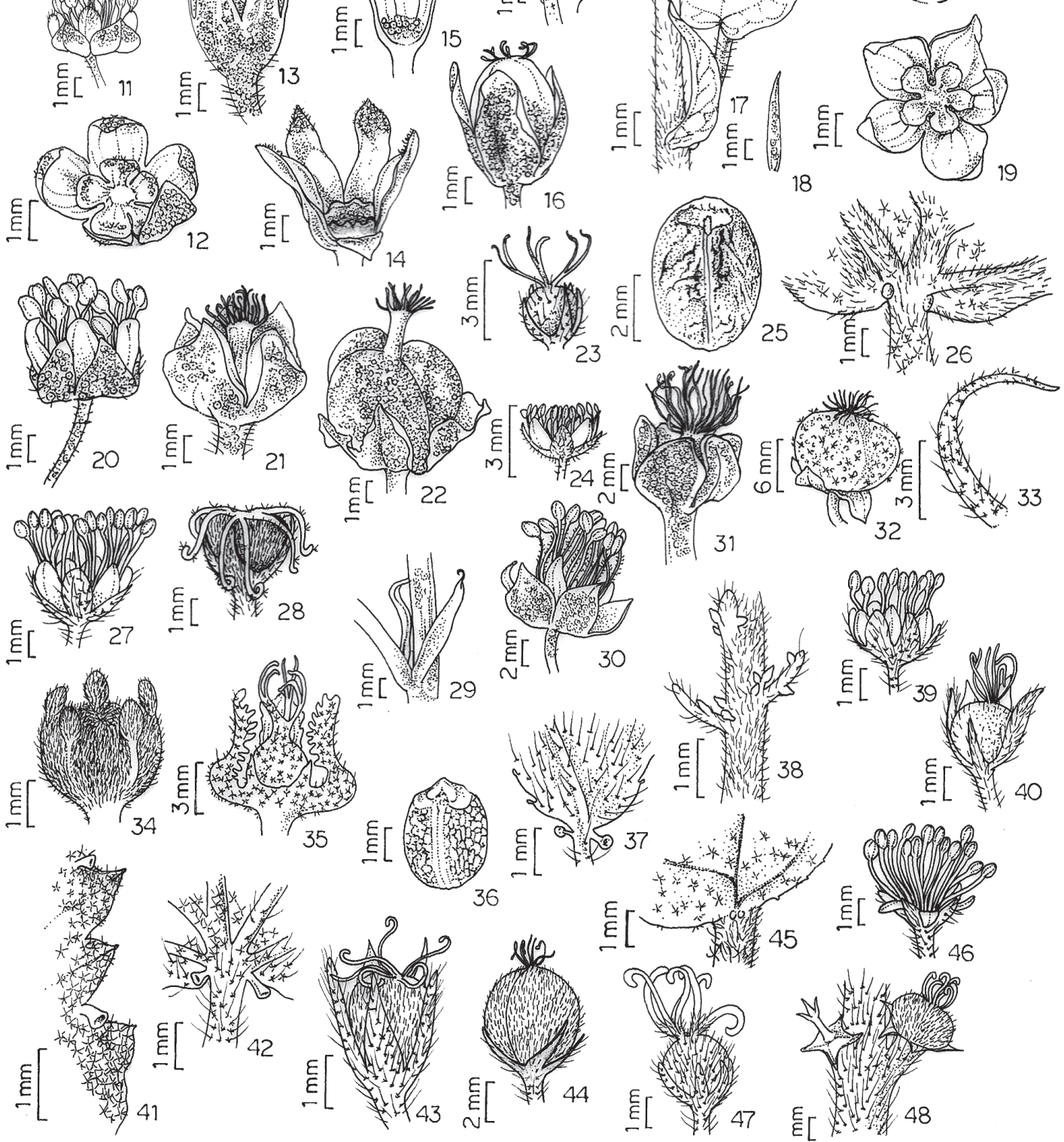

31

32
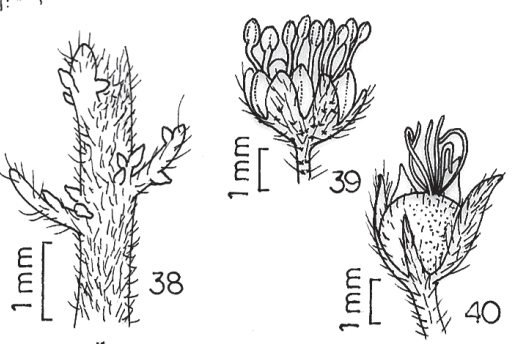

Figuras 1-4. Croton adamantinus Müll. Arg. (Silva et al. 270): 1. Detalhe da glândula na indentação. 2. Glândulas basilaminares. 3. Inflorescência. 4. Flor pistilada. 5-7. Croton adenocalyx Baill (Heringer et al. 894): 5. Detalhe das glândulas no ápice dos dentes. 6. Estípulas. 7. Flor pistilada. 8-10. Croton argenteus L. (Secco \& Rosa 898): 8. Flor pistilada. 9. Disco da flor pistilada. 10. Gineceu. 11-16. Croton argyrophyllus Kunth (Andrade et al. 267): 11. Flor estaminada. 12. Disco da flor estaminada. 13. Flor pistilada. 14-15. Disco da flor pistilada. 16. Fruto. 17-22. Croton blanchetianus Baill. (Santos s/n UFP 39344): 17-18. Estípulas. 19. Disco da flor estaminada. 20. Flor estaminada. 21. Flor pistilada. 22. Fruto. 23-25. Croton campestris A. St.-Hil. (Fotius 3761): 23 . Flor pistilada. 24. Flor estaminda. 25. Semente. 26-28. Croton echioides Baill. (Laurênio \& Gomes 2007): 26. Glândulas basilaminares. 27. Flor estaminada. 28. Flor pistilada. 29-32. Croton floribundus Spreng. (Laurênio 1615): 29. Estípula. 30. Flor estaminada. 31. Flor pistilada. 32. Fruto. 33-36. Croton fuscescens Spreng. (Silva 633): 33. Estípula. 34. Flor estaminada. 35. Flor pistilada. 36. Semente. 37-40. Croton glandulosus L. (Heringer et al. 119): 37. glândulas acropeciolares. 38 . Detalhe das glândulas nas brácteas. 39. Flor estaminada. 40. Flor pistilada. 41-44. Croton grewioides Baill. (Silva et al. 413): 41. Detalhe das glândulas nas indentações. 42. Glândulas acropeciolares. 43. Flor pistilada. 44. Fruto. 45-48. Croton heliotropiifolius Kunth (Andrade et al. 306): 45. Glândulas acropeciolares. 46. Flor estaminada. 47. Flor pistilada. 48. Fruto. 
Espécie sul-americana muito comum em bordas e clareiras de florestas mesófilas, ombrófilas e de matas ciliares do Brasil e do leste do Paraguai (Gomes 2006; Caruzo \& Cordeiro 2007). No Brasil, ocorre nas regiões Nordeste (AL, BA, CE, PE, RN), Sudeste (ES, MG, RJ, SP), Sul (PR) e Centro-oeste (MT). Na área de estudo, foi verificada desde a região litorânea até a semi-árida, nesta última sendo encontrada preferencialmente em áreas mais úmidas, sobre solo argiloso formando algumas vezes grandes populações.

Material selecionado: BRASIL: Pernambuco: Bezerros, caminho para reserva de Serra Negra, 12/IV/1999, fl. fr., Laurênio 1615 (PEUFR); Camaragibe, Aldeia, Km 12, 12/I/2004, fl., Gomes \& Laurênio 1532 (PEUFR); São Vicente Férrer, mata do Estado, 18/IV/1995, fr., Rodal et al. 513 (PEUFR)

10. Croton fuscescens Spreng., Syst. Veg. 3: 874. 1826. Fig. 33-36

Ocorre apenas no Brasil, habitando bordas e clareiras de florestas ombrófilas e mesófilas das regiões nordeste (AL, BA, PE, SE), sudeste (MG, RJ, SP) e centro-oeste (GO). Em Pernambuco foi encontrada nas zonas da Mata (floresta atlântica) e das Caatingas, crescendo em brejos de altitude na borda da mata, em solos úmidos e com serrapilheira.

Material selecionado: BRASIL: Pernambuco: Vitória de Santo Antão, engenho Pombal, 29/VII/1997, fl., Lucena 309 (PEUFR); Taquaritinga do Norte, 16/IV/2005, fl. fr., Silva 633 (PEUFR).

\section{Croton glandulosus L., Syst. Nat. 10: 1275. 1759.}

Fig. 37-40

Amplamente distribuida nas Américas, ocorrendo desde o centro e sudeste dos Estados Unidos até a Argentina (Govaerts et al. 2000). No Brasil, distribui-se da região Norte até o Sul (AL, AM, AP, BA, CE, ES, GO, MG, MS, MT, PA, PE, PI, PB, PR, RJ, RN, SC, SE, SP, TO) em diferentes ambientes: florestas, cerrados, caatinga e, ainda, como ruderal. Em Pernambuco é encontrada desde o litoral até a subzona do Sertão, em áreas cultivadas, terrenos baldios ou em bordas de mata.

Material selecionado: BRASIL: Pernambuco: Buíque, estrada para o Catimbau, 04/IX/2007, fl. fr., Silva \& Lima 267 (PEUFR); serra do Catimbau, 10/VII/1997, fr., Lucena et al. s.n (HUEFS 53294); Petrolina, 4/IV/1991, fl. fr., Nogueira et al. 1 (IBGE); Pombos, 23/VII/1998, fl., Lucena et al. 594 (PEUFR).

\section{Croton grewioides Baill., Adansonia 4: 365. 1864.} Fig. 41-44

Trata-se de uma espécie do semi-árido brasileiro, embora penetre no domínio da Floresta Atlântica em áreas antropizadas. Ocorre nos estados da Alagoas, Bahia, Ceará, Minas Gerais, Paraíba, Pernambuco, Piauí, Rio Grande do Norte, e
Sergipe. Em Pernambuco, foi verificada nas zonas da Mata e das Caatingas, crescendo em vegetação rupestre e de caatinga, em altitude que varia de $440 \mathrm{~m}$ a $600 \mathrm{~m}$.

Nome vulgar: caatinga-de-cheiro, canelinha ou alecrimde-cabloco

Material selecionado: BRASIL: Pernambuco: Buíque, estrada do Fortuoso, 11/II/2008, fl., Silva et al. 372 (PEUFR); Paraíso Selvagem, 14/II/2008, fl., Silva et al. 413 (HST, PEUFR); serra de Jerusalém, 14/II/2008, fl., Silva et al. 408 (HST, PEUFR); Pesqueira, Tribo Xucurú, aldeia Pedra d'água, 26/IV/1995, fl., Silva 14 (UFP); Saloá, fazenda Brejo, 23/XII/2001, fl., Lucena \& Falcão 933 (PEUFR); Pombos, Serra da Russa, 23/VII/1998, fl., Lucena et al 595 (UFP, PEUFR).

13. Croton heliotropiifolius Kunth, Nov. gen. sp. pl. (4) 2: 83. 1817.

Fig. $45-48$

Amplamente distribuída na região Neotropical, ocorrendo desde o Panamá até o Brasil (Govaerts et al. 2000). Neste último país é encontrada em praticamente toda região Nordeste estendendo-se até o estado de Minas Gerais (Lucena 2000), crescendo predominantemente em vegetação de caatinga, embora também ocorra em bordas de florestas serranas (brejos de altitudes, PE), restinga e cerrado. Na área de estudo é encontrada numa faixa contínua da zona da Mata até a zona das Caatingas, em vegetação de caatinga, brejos de altitude e floresta atlântica e, ainda, em terrenos baldios.

Nome vulgar: velame

Material selecionado: BRASIL: Pernambuco: Garanhuns, fazenda Monteiro, 21/X/1998, fl. fr., Melo 90 (PEUFR); São Lourenço da Mata, estação ecológica do Tapacurá, 13/III/1998, fl., Laurênio \& Santos 845 (PEUFR); São Lourenço da Mata, estação ecológica de Pedra Talhada, 23/XI/1999, fl. fr., Nascimento 281 (PEUFR); Serra Talhada, próxima a Baixa Verde, 16/VII/1998, fl., Lucena et al. 560 (PEUFR); Triunfo, sítio do Cigano, 16/VII/1998, fl., Lucena 565 (PEUFR).

\section{Croton hirtus L' Her., Stirp. Nov.: 17, pl. 9. 1785.}

Fig. 49-52

Espécie amplamente distribuída na região Neotropical, ocorrendo no Caribe, México até o norte da Argentina (Govaerts et al. 2000). No Brasil é referida como ruderal sendo verificada nas regiões Norte (PA), Nordeste (Al, BA, CE, MA, PE, PI, PB, RN), Centro-Oeste (DF, GO, TO), Sul (PR, RS, SC) e Sudeste (MG, SP) (Caruzo \& Cordeiro 2007). Em Pernambuco é encontrada formando pequenas populações nas zonas fitogeográficas do Litoral, da Mata e das Caatingas, crescendo em áreas cultivadas, próximo a habitações e em locais mais úmidos e elevados como nos brejos de altitude.

Material selecionado: BRASIL: Pernambuco: Taquaritinga do Norte, 18/IV/1997, fl. fr., Laurênio et al. 470 
(PEUFR); Recife, Curado, Jardim Botânico do Recife, 10/X/1998, fl. fr., Oliveira 372 (PEUFR).

15. Croton jacobinensis Baill., Andansonia 4: 302. 1864. Fig. 53-57

Restrita ao semi-árido brasileiro, ocorrendo na Bahia, Ceará, Minas Gerais, Paraíba, Pernambuco, Piauí e Rio Grande do Norte habitando áreas de caatinga, mata estacional e cerrado em altitudes que variam de $210 \mathrm{~m}$ a $845 \mathrm{~m}$. Na área de estudo, ocorre exclusivamente na zona da Mata, em bordas de mata e capoeiras.

Nome vulgar: velame-roxo ou velame-preto

Material selecionado: BRASIL: Pernambuco: São Lourenço da Mata, mata do Camocim, 18/X/1996, fl. fl., Lira 202 (PEUFR); Vitória de Santo Antão, engenho Pombal, 10/ III/1996, fl., Laurênio 342 (PEUFR).

16. Croton japirensis Müll. Arg., Linnaea 34: 122. 1865.

Ocorre exclusivamente no semi-árido brasileiro, sendo coletado na Bahia, Ceará, Pernambuco e Piauí. Desenvolvese, especialmente, em regiões com solo arenoso, podendo também ser encontrada em locais com afloramento de arenito. É uma espécie pouco freqüente na área de estudo, tendo sido coletada apenas no município de Petrolina, em terrenos baldios.

Material selecionado: BRASIL: Pernambuco: Petrolina, 18/IV/1971, fr., Academia Brasileira de Ciências 87 (IPA, HUEFS).

17. Croton laceratoglandulosus Caruzo \& Cordeiro, Bot.

J. Linnean Soc. 158: 493-498. 2008.

Fig. 58-61

Apresenta um padrão de distribuição disjunto entre a porção leste do Brasil (Bahia, Ceará, Minas Gerais, Piauí) e a porção leste da Bolívia (Santa Cruz) (Caruzo \& Cordeiro 2008). Ocorre principalmente em ambientes de caatinga e floresta seca, acima de $600 \mathrm{~m}$ de altitude. É registrada aqui pela primeira vez em Pernambuco, onde foi verificada apenas na zona das Caatingas (subzona do Sertão) crescendo em vegetação de caatinga sobre solo arenoso.

Material selecionado: BRASIL. Pernambuco: Salgueiro, 80 41'66'S, 39 91'67'W, 10/01/1998, fr., Silveira $s / n$ (HUEFS 111098).

18. Croton lundianus (Didr.) Müll. Arg., in DC, Prodr. 15 (2): 662.1866.

Podostachys lundiana Didr., Vidensk. Meddel. Dansk

Naturhist. Foren. Kjobenhavn part.8-10: 137. 1857.

Fig. 62-65

Espécie sul-americana com ocorrência na Argentina, Brasil e Paraguai. No Brasil ocorre em praticamente todo território Nacional (AL, BA, ES, GO, MA, MG, PA, PE, PI, PR, RJ, RO, SC, SE, SP, TO) crescendo em campo ru- pestre, caatinga, próximas às matas ciliares e no interior de capoeiras (Cordeiro 1992). Na área estudada é comumente encontrada em bordas de mata, áreas de caatinga e margem de estradas das zonas do Litoral, da Mata e das Caatingas (subzona do Agreste).

Material selecionado: BRASIL. Pernambuco: Buíque, Paraíso Selvagem, 17/IX/2007, Silva \& Lima 291 (PEUFR); Camaragibe, loteamento Açude Timbi, 10/II/1998, fl. fr., Lucena 714 (PEUFR); Paudalho, Guadalajara, engenho São João, 10/VIII/1998, fr., Lucena 615 (PEUFR).

19. Croton nepetifolius Baill., Adansonia 4: 344. 1864.

Fig. 70-71

Espécie restrita ao semi-árido brasileiro, ocorrendo em ambientes abertos e secos da caatinga e cerrados, nos estados de Alagoas, Bahia, Ceará, Paraíba, Pernambuco, Piauí, Rio Grande do Norte e Sergipe, embora também seja verificada em capoeiras e áreas de transição caatinga-cerrado. Em Pernambuco foi encontrada, até o momento, na subzona do Sertão, crescendo em vegetação de caatinga em solo arenoso.

Nome vulgar: malva-preta ou canelinha-de-areia

Material selecionado: BRASIL. Pernambuco: Exu, Chapada do Araripe, 4/IV/2001, fr., Harley, Giulietti \& Virgínio 5414 (HUEFS); Mirandiba, fazenda Areias, 31/V/2006, fl., Lucena, Córdula \& Maciel 800 (UFP); Petrolândia, Chapada do Araripe, 12/XII/1988, fr., Fotius 3647 (IPA).

20. Croton nummularius Baill., Adansonia 4: 360. 1864. Fig. $72-77$

Espécie disjunta entre a Cadeia do Espinhaço (BA, MG) e Pernambuco, crescendo em vegetação de caatinga e cerrado. Em Pernambuco apresenta distribuição restrita ao município de Buíque, com ocorrência apenas em formações rupestres.

Material selecionado: BRASIL. Pernambuco: Buíque, Paraíso Selvagem, 8/III/1996, fl. fr., Laurênio et al. 351 (PEUFR); Buíque, serra de Jerusalém, 14/II/2008, fl. fr., Silva et al. 404 (HST, PEUFR).

21. Croton polyandrus Spreng., Neue Entd. 2: 120. 1821. Fig. 78-81

Restrita ao Nordeste do Brasil, ocorrendo nos estados de Alagoas, Bahia, Paraíba e Pernambuco, em vegetação de restinga. $\mathrm{Na}$ área de estudo foi verificada apenas na faixa litorânea, habitando ambientes abertos da restinga sobre solo arenoso.

Material selecionado: BRASIL. Pernambuco: Goiana, Ponta de Pedra, 9/IV/1989, fl., Guedes \& Moura 1717 (PEUFR). Jaboatão dos Guararapes, Praia de Piedade, 14/ VI/1950, fl. fr., Leal 71 (RB).

22. Croton rhamnifolioides Pax \& K. Hoffm., Repert. Spec. Nov. Regni Veg. 19: 174. 1923.

Fig. 82-83 


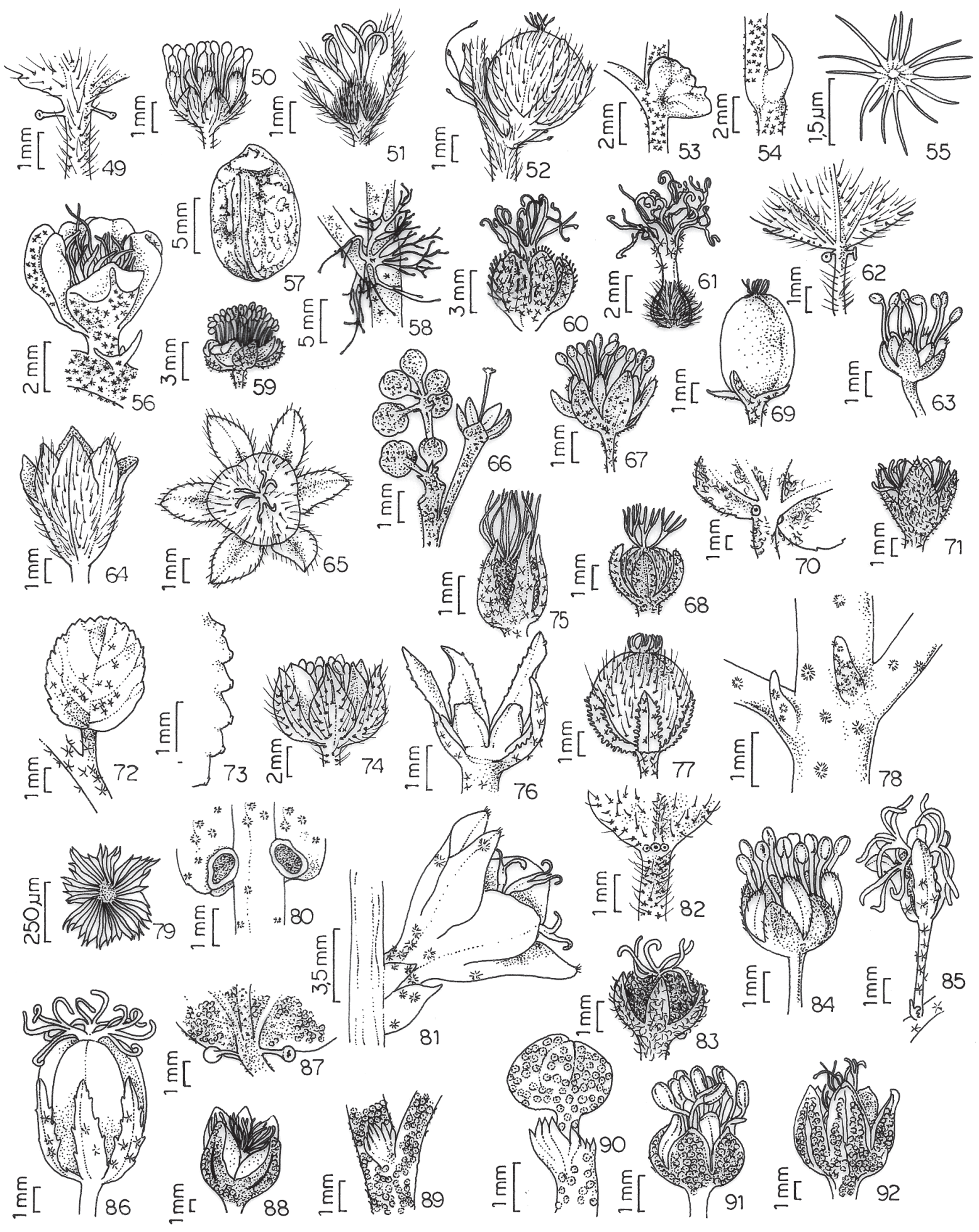

Figuras 49-52. Croton hirtus L' Hér. (Carvalho 36): 49. Glândulas acropeciolares. 50. Flor estaminada. 51. Flor pistilada. 52. Fruto. 53-57. Croton jacobinensis Baill. (Laurênio 342): 53-54. Estípulas. 55. Tricoma estrelado-rotado da face dorsal foliar. 56. Flor pistilada. 57. Semente. 58-61. Croton laceratoglandulosus Caruzo \& Cordeiro (retirada de Cordeiro et al. 2008): 58. Estípula. 59. Flor estaminada. 60. Flor pistilada. 61. Gineceu. 62-65. Croton lundianus (Didr.) Müll. Arg. (Sales et al. 497): 62. Glândulas acropeciolares. 63. Flor estaminada. 64. Flor pistilada. 65. Fruto. 66-69. Croton corchoropsis Baill. (Laurênio \& Gomes 123): 66. Inflorescência. 67. Flor estaminada. 68. Flor pistilada. 69. Fruto. 70-71. Croton nepetifolius Baill. (Harley, Giulietti \& Virgínio 5414 ): 70. Glândulas basilaminares. 71. Flor pistilada. 72-77. Croton nummularius Baill. (Silva et al. 404): 72. Folha. 73. Margem laminar. 74. Flor estaminada. 75. Flor pistilada. 76. Disco da flor pistilada. 77. Fruto. 78-81. Croton polyandrus Spreng. (Guedes \& Moura 1717): 78. Detalhe do ramo com as estípulas. 79. Tricoma dentado-lepidoto. 80. Glândulas basilaminares. 81. Flor pistilada. 82-83. Croton rhamnifolioides Pax \& K. Hoffm. (Gomes, Laurênio \& Figueiredo 370): 82. Glândulas acropeciolares. 83. Flor pistilada. 84-86. Croton rudolphianus Müll. Arg. (Gomes \& Laurênio 112): 84. Flor estaminada. 85. Flor pistilada. 86. Fruto. 87-88. Croton salutaris Casar. (Nascimento \& Silva 362): 87. Glândulas acropeciolares. 88. Flor pistilada. 89-92. Croton sellowii Baill. (retirada de Lucena 2000): 89. Detalhe do ramo mostrando a estípula. 90. Detalhe da bráctea. 91. Flor estaminada. 92. Flor pistilada. 
Ocorre no estado da Bahia (Govaerts et al. 2000) e de Pernambuco, crescendo em vegetação de caatinga. Em Pernambuco foi observada na zona das Caatingas em áreas antropizadas e de vegetação de caatinga, sobre solo arenoargiloso ou arenoso.

Nome vulgar: Velame.

Material selecionado: BRASIL. Pernambuco: Buíque, fazenda Laranjeiras, 7/12/1996, fl., Gomes, Laurênio \& Figueiredo 370 (PEUFR); Serra Talhada, 5/II/1998, fl., Santos, Gomes \& Figueiredo 74 (PEUFR).

23. Croton rudolphianus Müll. Arg., in DC., Prodr. 15(2): 654. 1866.

Fig. 84-86

É encontrada nos estados de Alagoas, Bahia, Ceará, Minas Gerais, Pernambuco e Sergipe, crescendo em vegetação de caatinga e campo rupestre. Na área de estudo, até o momento, foi apenas coletada no complexo de serras da chapada de São José (Buíque), em vegetação rupestre e de caatinga, em altitudes que variam $600 \mathrm{~m}$ a $1000 \mathrm{~m}$.

Material selecionado: BRASIL. Pernambuco: Buíque, chapada de São José, 8/V/2003, fl., Gomes \& Laurênio 1124 (PEUFR); Paraíso Selvagem, 14/II/2008, fl., Silva et al. 412 (PEUFR); serra Branca, 12/II/2008, fl., Silva et al. 377 (PEUFR).

24. Croton salutaris Casar., Nov. stirp. bras. 89. 1845.

Fig. 87-88

Ocorre nos estados do Espírito Santo, Minas Gerais, Pernambuco e Rio de Janeiro em regiões de floresta ombrófila, mata ciliar e floresta montana (PE). Na área de estudo, foi observada apenas no município de Brejo da Madre de Deus crescendo em bordas de mata e clareiras, acima 900 $\mathrm{m}$ de altitude.

Material selecionado: BRASIL. Pernambuco: Brejo da Madre de Deus, Mata do Bituri, 28/III/2000, fl., Nascimento \& Silva 362 (PEUFR).

25. Croton sellowii Baill., Adansonia 4: 304. 1864.

Fig. 89-92

Ocorre, predominantemente, associada à vegetação de restinga nos estados de Alagoas, Bahia, Paraíba, Pernambuco e Sergipe (Gomes 2006). Em Pernambuco foi verificada na zona do Litoral, formando densas populações sobre solos tipicamente arenosos ou em fendas de rochas.

Material selecionado: BRASIL. Pernambuco: Araçoiaba, mata da Vila Militar, 11/VIII/1998, fl., Lucena et al. 620 (PEUFR); Recife, Boa Viagem, 27/VI/1987, fl., Schwacke $623(\mathrm{RB})$.

26. Croton sincorensis Mart. ex Müll. Arg., in Mart., Fl. Bras. 11 (2): 86. 1873.

Fig. 93-94
Distribui-se nas florestas estacionais semideciduais da Cadeia do Espinhaço (BA, MG) e na Mata Atlântica da Bahia, Espírito Santo e Pernambuco, sobre solo arenoso e argiloso, entre 300 e 1.000 metros de altitude. Em Pernambuco é uma espécie conhecida por poucas coletas, sendo encontrada apenas na zona do Litoral (Camaragibe) e da Mata (Vicência) em área de capoeira e bordas de mata.

Material selecionado: BRASIL. Pernambuco: Camaragibe, Aldeias, 24/VII/1950, fl., Andrade-Lima 615 (IPA); Vicência, Pirauá, 29/XI/1959, fl., Andrade-Lima 2838 (IPA).

27. Croton sp. A. P. S. Gomes \& M. F. Sales (sp. nova inéd., submetida)

Fig. 95-99

Restrita ao semi-árido brasileiro, onde cresce em chapadas, chapadões e serras de formações areníticas nos estados da Bahia, Ceará, Paraíba, Pernambuco, Piauí e Rio Grande do Norte, entre 400 e 1350 metros de altitude. Na área de estudo é encontrada na chapada do Araripe, crescendo em vegetação de caatinga.

Material selecionado: BRASIL. Pernambuco: Araripina, 3,5 Km da Estação Experimental do IPA, 14/II/1998, fl., Ferreira s/n (IPA 61887).

28. Croton tetradenius Baill., Adansonia 4: 343. 1864.

Fig. 100-103

Trata-se de uma espécie endêmica da região Nordeste, ocorrendo em vegetação de caatinga nos estados de Alagoas, Bahia, Ceará, Paraíba, Pernambuco, Rio Grande do Norte e Sergipe (Carneiro-Torres 2009). Na área de estudo, foi verificada em capoeira, caatinga, brejos de altitudes e em áreas antropizadas da zona das Caatingas.

Material selecionado: BRASIL: Pernambuco: Arcoverde, serra das Varas, 4/II/1981, fl., Krapovickas, Critóbal \& Andrade-Lima 3846 (IPA); Triunfo, 26/II/1986, fl. fr., Lima \& Gallindo 120 (IPA).

29. Croton tricolor Klotzsch ex Baill., Adansonia 4: 291. 1864.

Fig. 104-108

Apresenta padrão de distribuição disjunto entre a porção norte da América do Sul (Colômbia, Venezuela) e a porção leste do Brasil (Alagoas, Bahia, Ceará, Minas Gerais, Paraíba, Pernambuco, Piauí, Sergipe, São Paulo, Paraná) (Gomes 2006). Na área estudada, ocorre em ambientes xéricos integrando a vegetação de caatinga sobre solo arenoso ou pedregoso. É mencionada principalmente para serras e chapadas de origem sedimentar (Chapada do Araripe, Serra Negra no município de Floresta).

Nome vulgar: marmeleiro

Material selecionado: BRASIL. Pernambuco: Exu, chapada do Araripe, serra do Ingá, $7^{\circ} 21^{\prime} 6^{\prime \prime} \mathrm{S}, 39^{\circ} 45^{\prime} 58^{\prime \prime} \mathrm{W}$, 
4/IV/2001, fl., Harley, Giulietti \& Virginio 54161 (HUEFS); Ibimirim, estrada para Serra Negra, 22/III/1994, fl., Silva 347 (PEUFR); São José do Belmonte, próximo à Malhada, 25/IV/2003, fl. fr., Gomes et al. 835 (PEUFR).

30. Croton tridentatus Mart. ex Müll. Arg. in Mart., Fl. Bras. 11(2):219. 1873.

Fig. 109-110

Restrita ao semi-árido brasileiro, ocorrendo em vegetação de caatinga sobre solo arenoso na Bahia, Pernambuco e Sergipe. Em Pernambuco, foi verificada crescendo em vegetação de caatinga, em locais parcialmente inudados ou em áreas ribeirinhas.

Material selecionado: BRASIL. Pernambuco: Petrolina, $5 \mathrm{Km}$ Norte CPATSA, 11/VIII/1983, fl. fr., Fotius 3544 (IPA); Trindade, lagoa Trindade, 18/V/1983, fl. fr., Cavalcanti $s / n$ (IPA 45430).

31. Croton trinitatis Millsp., Publ. Field. Mus. Nat. Hist., Bot. Ser. 2: 57. 1900.

Fig. 111-113

Apresenta ampla distribuição nas Américas, estendendo-se desde o México até o Paraguai (Govaerts et al. 2000). No Brasil, distribui-se da região Norte a Sul. Cresce em diferentes ambientes desde floresta atlântica, cerrado, caatinga e, ainda, em beira de estrada, margem de rios e capoeiras. Em Pernambuco é encontrada nas zonas do Litoral e da Mata, em beiras de estrada, áreas de pastagens e de agricultura.

Material selecionado: BRASIL. Pernambuco: Bonito, 23/VII/1998, fl., Lucena 601 (IPA); Ipojuca, 10/XI/1986, fl., Webster \& Dehgan s/n (IPA 49503).

32. Croton triqueter Lam., Encycl. Menth. 2: 214. 1786.

Fig. 114-117

Espécie neotropical, distribuindo-se na Argentina, Bolívia, Brasil e Paraguai. No Brasil é referida para a região Centro-Oeste (GO, MS), Nordeste (BA, CE, MA, PE, SE), Norte (PA, RR,), Sudeste (ES, MG, RJ, SP) e Sul (PR, RS, SC), comumente em bordas de florestas ombrófilas e mesófilas (Caruzo \& Cordeiro 2007). Em Pernambuco, é observado apenas na zona da Mata norte crescendo em áreas antropizadas sobre solo arenoso.

Material selecionado: BRASIL. Pernambuco: Buenos Aires, 15/V/1999, fl., Lucena \& Loiola 733 (PEUFR); Vitória de Santo Antão, engenho Pombal, 3/III/1998, fl., Laurênio 1307 (PEUFR).

33. Croton urticifolius Lam., Encycl. Menth 2:219.1786. Fig. 118-122

Ocorre, predominantemente, associada à ambientes secos do Brasil. Distribuindo-se nas regiões Nordeste (AL, BA, CE, PI, PE, PB, RN, SE), Norte (AM, PA) e
Sudeste (ES, MG, RJ), em vegetação de caatinga, floresta decídua e campo rupestre (Carneiro-Torres 2009). Em Pernambuco, estende-se da zona da fitogeográfica da Mata até a zona fitogeográfica das Caatingas (Agreste), habitando bordas de mata, áreas degradadas e margem de estradas.

Material selecionado: BRASIL. Pernambuco: Bonito, 7/XI/2008, fl., Albuquerque 11 (IPA); Garanhuns, fazenda Monteiro, 18/VIII/1998, fl. fr., Lucena et al. 640 (PEUFR).

\section{Croton velutinus Baill., Andansonia 4: 325. 1864.}

Fig. 123-125

Espécie disjunta entre a Cadeia do Espinhaço (Bahia e Minas Gerais) e o semi-árido pernambucano, ocorrendo em campos rupestres e cerrados sobre solo arenoso, entre 500 a 1400 metros de altitude. Em Pernambuco, foi observada apenas em vegetação de caatinga, em áreas antropizadas sobre solo arenoso.

Material selecionado: BRASIL. Pernambuco: Ibimirim, 8/XI/1986, fl. fr., Webster 25729 (IPA). Material Selecionado Adicional: BRASIL. Bahia: Rio de Contas, 20/X/1997, fl. fr., Alves et al. 600 (PEUFR).

35. Croton virgultosus Müll. Arg., in Mart., Fl. bras. 11 (2): 104.1873.

Fig. 126-129

É encontrada nos estados do Bahia, Ceará, Minas Gerais, Pernambuco, Piauí e Rio Grande do Norte, crescendo em vegetação de caatinga e floresta estacional (CarneiroTorres 2009). Na área estudada, foi verificada apenas no munícipio de Buíque integrando a vegetação arbustiva sobre solo arenoso.

Material selecionado: BRASIL. Pernambuco: Buíque, estrada para o sítio Breu, 12/II/2008, fl., Silva et al. 391 (PEUFR); serra do Catimbau, 15/III/2005, fl., Pick 159 (UFP); trilha da Igrejinha, 12/II/2008, fl., Silva et al. 383 (PEUFR).

Espécie não incluída:

Croton odoratus Ridl. foi descrita para o Arquipélago de Fernando de Noronha, distrito pernambucano. Caracteriza-se pela folhas ovais com margem denteada, estípulas glandulares, sépalas das flores estaminadas em número de 10 e estames 9 (Ridley 1890). Assemelha-se a Croton rudolphianus Müll. Arg. e provavelmente pertence à seção Barhamia (Klotzsch) Baill. Essa espécie não foi incluída nesse trabalho pela dificuldade de acesso a ilha e pela falta de material (exsicatas) nos herbários do Estado.

\section{Agradecimentos}

Ao Conselho Nacional de Desenvolvimento Científico e Tecnológico $(\mathrm{CNPq})$, pela bolsa de estudo concedida à primeira autora; ao Programa de Pós-graduação em Botânica - UFRPE, pelo apoio institucional e logístico; à Franck Silva, pelo auxílio nas ilustrações; aos curadores dos herbários citados, pelo livre acesso as suas instalações e aos dois assessores, pelas suas sugestões. 

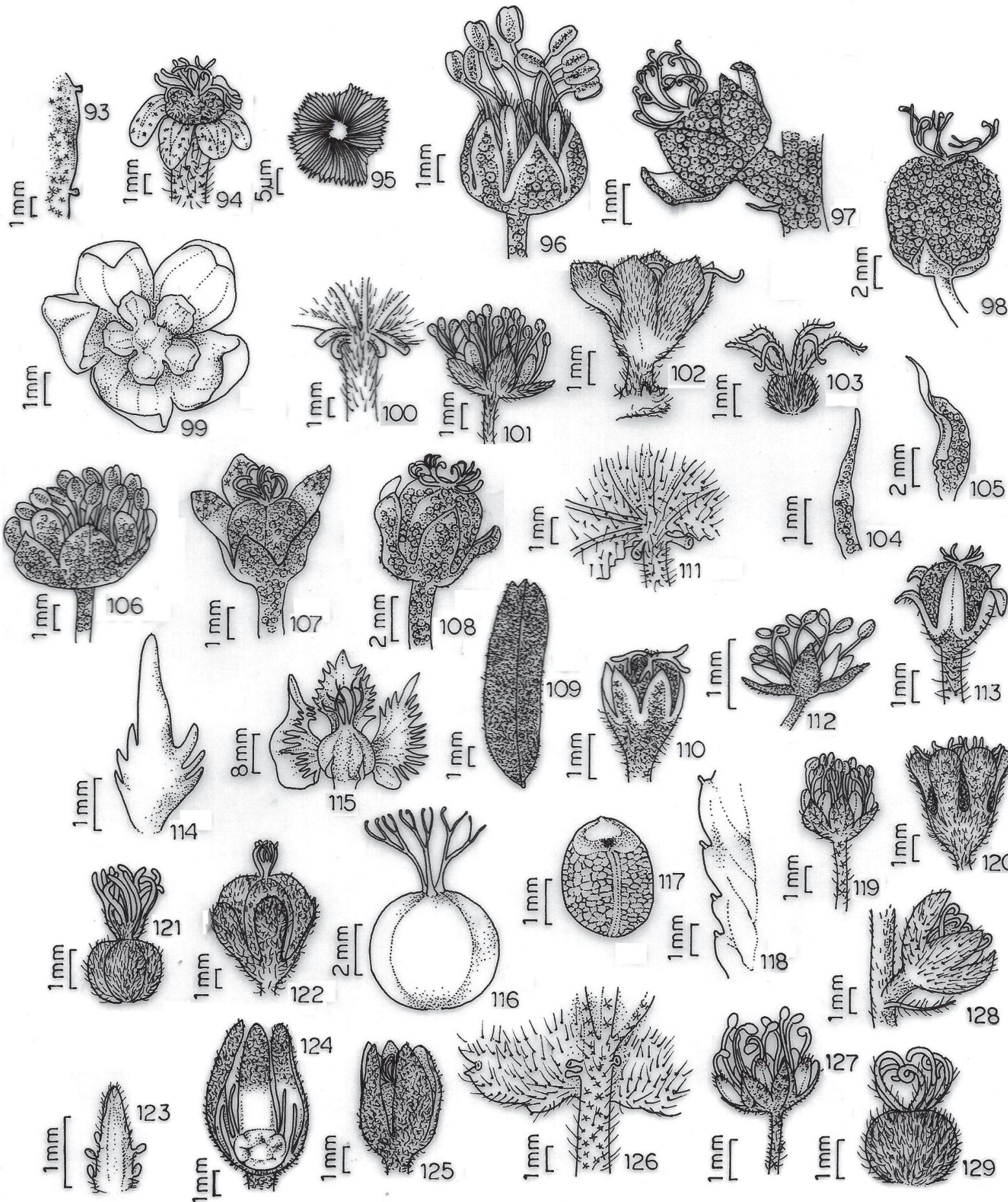

$\sim L 108$

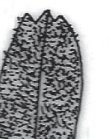

109
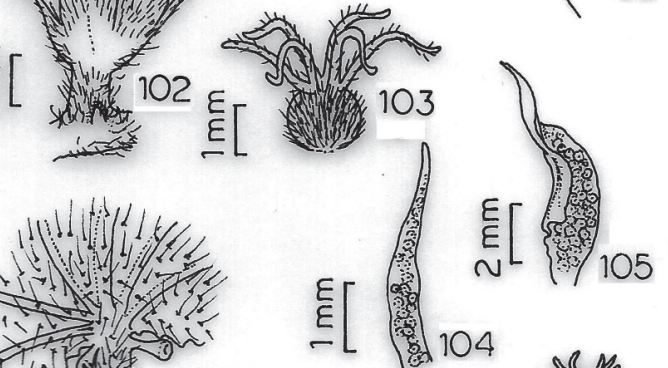

104
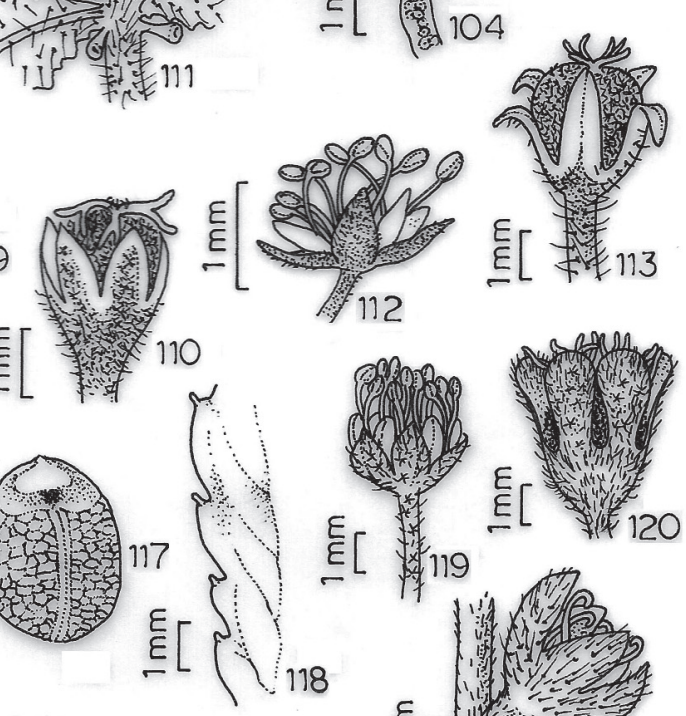

E[ 溥119
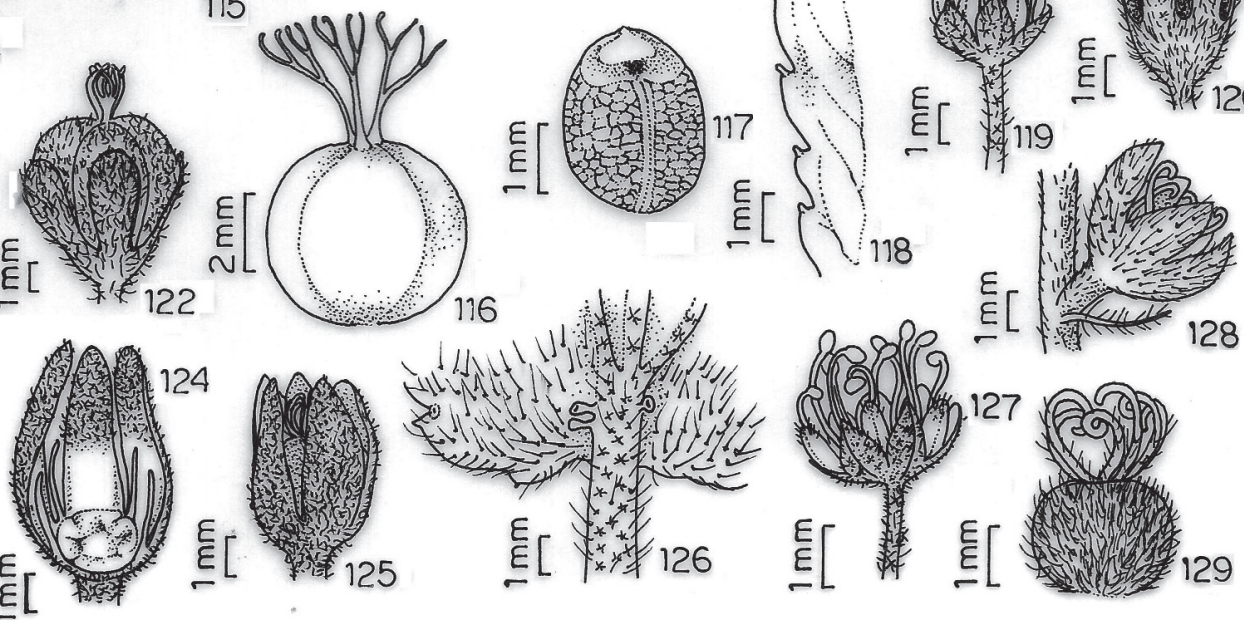

Figuras 93-94. Croton sincorensis Mart. ex Müll. (Andrade-Lima 615): 93. Detalhe das glândulas na margem laminar. 94. Flor pistilada. 95-99. Croton sp. (Ferreira $s / n$ - IPA 61887): 95. Tricoma lepidoto. 96. Flor estaminada. 97. Flor pistilada. 98. Fruto. 99. Disco da flor pistilada. 100-103 Croton tetradenius Baill. (AndradeLima 5624): 100. Glândulas acropeciolares. 101. Flor estaminada. 102. Flor pistilada. 103. Gineceu. 104-108. Croton tricolor Klotzsch ex Baill. (Gomes et al. 835): 104-105. Estípulas. 106. Flor estaminada. 107. Flor pistilada. 108. Fruto. 109-110. Croton tridentatus Mart. ex Müll. (Fotius 3544): 109. Folha. 110. Flor pistilada. 111-113. Croton trinitatis Millsp. (Paiva Júnior 18): 111. Glândulas acropeciolares. 112. Flor estaminada. 113. Flor pistilada. 114-117. Croton triqueter Lam. (Lucena \& Loiola 733): 114. Bráctea. 115. Flor pistilada. 116. Gineceu. 117. Semente. 118-122. Croton urticifolius Lam. (Costa 27): 118. Margem laminar. 119. Flor estaminada. 120. Flor pistilada. 121. Gineceu. 122. Fruto. 123-125. Croton velutinus Baill. (Andrade-Lima s/n - IPA 6160): 123. Bráctea. 124. Disco da flor pistilada. 125. Flor pistilada. 126-129. Croton virgultosus Müll. Arg. (Silva et al. 383): 126. Glândulas basilaminares. 127. Flor estaminada. 128. Flor pistilada. 129. Gineceu. 


\section{Referências bibliográficas}

Andrade-Lima, D. 1957. Estudos Fitogeográficos de Pernambuco. Arquivos do Instituto de Pesquisas Agronômicas 5: 305-341.

Baillon, H. 1864. Species Euphorbiacerum Euphorbiacées Américaines. Adansonia 4: 257-377.

Berry, P. E.; Hipp, A. L., Wurdack, K. J.; Van Ee, B. W. \& Riina, R. 2005. Molecular phylogenetics of the giant genus Croton and tribe Crotoneae (Euphorbiaceae sensu stricto) using ITS and $t r n L-\operatorname{trn} F$ sequence data. American Journal of Botany 92: 1520-1534.

Carneiro, D. S.; Cordeiro, I. \& França, F. 2002. A família Euphorbiaceae na flora de inselbergs da região de Milagres, Bahia, Brasil. Boletim de Botânica da Universidade de São Paulo 20: 31-47.

Carneiro-Torres, D. S. 2009. Diversidade de Croton L. (Euphorbiaceae) no bioma Caatinga. Tese Doutorado. Universidade Estadual de Feira de Santana, Feira de Santana.

Caruzo, M. B. R. \& Cordeiro, I. 2007. Sinopse da tribo Crotoneae Dumort. (Euphorbiaceae s.s.) no Estado de São Paulo, Brasil. Hoehnea 34 (4): 571-585.

Cordeiro, I. 1995. Euphorbiaceae. In: Stannard, B.L. (ed.). Flora do Pico das Almas, Chapada Diamantina, Bahia-Brasil. Kew, Royal Botanic Gardens. p. 300-317.

Cordeiro, I.; Berrey, P. E.; Caruzo, M. B. R. \& Van Ee, B. W. 2008. Croton laceratoglandulosus (Euphorbiaceae s.s.), a new glandular-stipulate species from Brazil and Bolivia, and its systematic position based on molecular analysis. Botanical Journal of the Linnean Society 158: $493-498$

Govaerts, R.; Frodin, D. G. \& Radcliffe-Smith, A. 2000. Croton. Pp. $417-$ 536. In: World Checklist and bibliography of Euphorbiaceae (and Pandaceae). Kew, Royal Botanic Gradens Kew.

Grisebach, A. H. R. 1864. Croton. Flora of the British West Indian Islands, London.
Harris, J. G. \& Harris, M. W. 1994. Plant identification terminology. 2 ed An illustrated glossary. Spring Lake.

Lucena, M. F. A. Estudos taxonômicos do gênero Croton $L$. (Crotonoideae-Euphorbiaceae) nas zonas do Litoral e da Mata do estado de Pernambuco - Brasil. 2000. 136 f. Dissertação (Mestrado em Botânica) - Universidade Federal Rural de Pernambuco, Recife.

Mori, S. A.; Silva, L. A. M.; Lisboa, G. \& Corandin, L. 1989. Manual de manejo do herbário fanerogâmico. Ilhéus. Centro de Pesquisa do Cacau.

Müller, J. A. 1865. Euphorbiaceae. Linnaea 34: 77-142.

Müller, J. A. 1866. Croton In: De Candolle, A. P. (ed) Prodromus systematis naturalis regni vegetabilis 15: 511-708.

Radford, A.E.; Dickson, W. C. \& Massey, J. R. 1974. Vascular plant systematics. New York, Happer \& Row Publishers.

Ridley, H.N. 1890. Notes on the botany of Fernando de Noronha. Botanical Journal of the Linnean Society 27: 58-59.

Sales, M. F.; Mayo, S. J. \& Rodal, M. J. N. 1998. Plantas vasculares das Florestas Serranas de Pernambuco. Recife, Universidade Federal Rural de Pernambuco.

Silva, J. S.; Sales, M. F. \& Carneiro-Torres, D. S. 2009 O gênero Croton (Euphorbiaceae) na microrregião do Vale do Ipanema, Pernambuco, Brasil. Rodriguésia 60 (4): 879-901.

Webster, G. L. 1992. Realigments in American Croton (Euphorbiaceae) Novon 2: 269-273.

Webster, G. L. 1993. A provisional synopsis of the section of the genus Croton (Euphorbiaceae). Taxon 42: 793-823.

Webster, G. L 1994. Synopsis of the genera and suprageneric tax of Euphorbiaceae. Annals of the Missouri Botanical Garden 81: 33-144.

Wurdack, K. J.; Hoffmann, P. \& Chase, M. W. 2005. Molecular phylogenetic analysis of uniovulate Euphorbiaceae (Euphorbiaceae sensu stricto) using plastid $r b c L$ and $t r n L-F$ DNA sequences. American Journal of Botany 92: 1397-1420. 